\title{
Process optimisation of non-cyanide
}

\section{Ag-PTFE metal matrix composite plating for threaded connections}

\section{Sieh, $\mathrm{R}$}

http://hdl.handle.net/10026.1/3514

\subsection{9/0020296715Z.000000000256}

Transactions of the Institute of Materials Finishing Maney Publishing

All content in PEARL is protected by copyright law. Author manuscripts are made available in accordance with publisher policies. Please cite only the published version using the details provided on the item record or document. In the absence of an open licence (e.g. Creative Commons), permissions for further reuse of content should be sought from the publisher or author. 
Accepted for publication in Transactions of Institute of Materials Finishing, doi: 10.1179/0020296715Z.000000000256

Process Optimisation of non-cyanide Ag-PTFE metal matrix composite electroplating for threaded connections

\author{
R. Sieh, H. R. Le ${ }^{\star}$, A. M. Cree \\ School of Marine Science and Engineering, Plymouth University, Plymouth, \\ United Kingdom
}

*Corresponding author - E-mail address: huirong.le@plymouth.ac.uk

\title{
Abstract:
}

Silver-PTFE metal matrix composite coatings were deposited onto ANSI 304 stainless steel to assess the potential of using a novel non-cyanide electroplating process to produce a corrosion resistant, self-lubricating composite coating. During this study, 32 different bath parameter sets, derived from 5 variables were used to develop the non-cyanide electroplating process without the use of a surfactant or strike. SEM/EDS as well as XPS microscopy equipment was used to analyse the samples. In addition, the functional characteristic and adhesion strength of the coating was assessed using a bi-directional tribometer (to measure the coefficient of friction) and a pull-off test conducted on an Instron tensile test machine. The experimental results revealed that a friction coefficient of 0.23 was achievable $(62 \%$ improvement over pure silver coating) where adhesion strength is not a primary consideration. For solid lubrication applications requiring high coating adhesive strength, the maximum adhesion strength achieved for the silver-PTFE composite coating was $2.5 \mathrm{MPa}$ ( $44 \%$ reduction over pure silver coating) with a friction coefficient of 0.32 achieved ( $47 \%$ improvement over pure silver coating).

Keywords: Non-cyanide silver electroplating; Composite coating; Adhesion; Tribology; PTFE. 
Accepted for publication in Transactions of Institute of Materials Finishing, doi: 10.1179/0020296715Z.000000000256

\subsection{Introduction}

Surface coatings on metals are typically applied to alter the surface properties of a surface (substrate) to improve its decorative and functional aspects as part of the finishing process. Decorative aspects may include physical aesthetics while functional aspects include improved chemical resistance and mechanical properties. These coatings may have decorative, functional or even dual purposes and often metals such as gold, silver, copper or nickel can be deposited on a substrate. These coatings are typically in the form of thin film depositions and range from nanometre thicknesses to micrometre thicknesses. To deposit the thin film onto a metal substrate, chemical or physical deposition processes may be used. Chemical deposition methods typically involve a fluid precursor which deposits a thin film after undergoing a chemical reaction to leave a solid layer. The physical deposition method on the other hand uses mechanical, electromagnetic or thermodynamic methods to produce a thin film [1-3].

\subsection{Silver Electroplating}

Silver and gold plating is primarily used in industry, with silver consumption for electronic and electric industries increasing from 4.26 tons in 2001 to 6.21 tons in 2007 [4]. Electroplating is an established surface coating process which deposits metal on a conductive surface, typically carried out using either a constant voltage or current. It was first achieved through a silver-cyanide solution patented by the Elkington brothers in 1840 [5]. Silver electroplating can be used to increase wear and abrasion resistance, corrosion protection, aesthetics, lubricity, etc. The silver electroplating process improves the properties of conductive metals through the thin film of silver deposited, which is a more corrosion resistant metal to the base metal 
Accepted for publication in Transactions of Institute of Materials Finishing, doi: 10.1179/0020296715Z.000000000256

[6]. Key electroplating process parameters include electrolyte composition, particle characteristics, current density, flow conditions and geometry of both the electroplating tank and electrodes [7]. The process is widely used in industry due to relatively simple principles of operation as well as ease of scalability for the process.

\subsection{Issues with electroplating toxicity for cyanide silver electroplating}

The major drawback to Elkington's silver electroplating solution is that it requires the use of cyanide in the electroplating bath [5]. Cyanide is both dangerous and noxious, so that the wastes as an output of the electroplating process require that cyanide as a poisonous substance to be carefully controlled from storage to use and ultimately disposal. The disposal of cyanide in industry is through further chemical processing. This typically involves either complete destruction with chlorine gas or conversion into the less poisonous cyanate $[5,6]$. The use of cyanide in silver electroplating baths has traditionally been unavoidable due to its commercial feasibility as well as its ability of producing high quality electroplated surfaces. In light of the problems associated with cyanide in silver electroplating baths, suitable and stable cyanide free silver electroplating bath alternatives have been proposed over the years. These include groups containing simple salts, inorganic complexes and organic complexes [5].

\subsection{Cyanide alternatives to silver electroplating and its issues}

Due to its toxicity, cyanide alternatives to silver electroplating have been the topic of investigation for quite some time, but it was only in the $20^{\text {th }}$ century that cyanide alternatives to silver electroplating had a breakthrough, with the baths being able to produce mirror bright and ductile surface finishes while also being to adhere sufficiently to substrates upon which the silver film is being deposited [8]. These 
Accepted for publication in Transactions of Institute of Materials Finishing, doi: 10.1179/0020296715Z.000000000256

cyanide alternatives can be subdivided into three distinct groups by the type of compound used, namely simple salts, inorganic complexes and organic complexes [5]. Initial attempts at eliminating cyanide from silver electroplating have failed to meet the quality of surface finish produced by a cyanide bath. Out of the cyanide alternative options, only the inorganic complex thiosulfate and organic complex succinimide have been successfully adopted for selective commercial use [9].

There are also issues with cyanide alternatives to silver electroplating. These include the high costs of raw materials for inorganic complexes, limited application of only a few metals, and poor adhesion without prior processing using a silver strike [9]. Strikes are special, micrometre thin plating deposits of a compatible metal that will serve as a foundation between the subsequent plating process and the substrate metal. Morrissey and Blair have independently reported poor quality of deposits obtained from organic complexes, i.e. due to tarnishing, relative to the quality of deposits obtained from cyanide electrolytes [5, 9]. In addition to that, commercial operators who intend to use succinimide as a cyanide alternative for silver electroplating would have to periodically adjust the solution bath $\mathrm{pH}$ due to the hydrolysis of succinimide which reduces the operating $\mathrm{pH}$ of between $7.5-9$ over time [10].

The reports of attempts to find a cyanide alternative to silver electroplating provide a useful insight into possible cyanide alternatives to silver electroplating as well as operational conditions. However, the analysis of cyanide alternative silver electroplating attempts often focus on decorative aspects such as the quality of the deposits through tarnish resistance and physical appearance. With the increasing use of surface coating to improve performance over existing substrate materials, 
Accepted for publication in Transactions of Institute of Materials Finishing, doi: 10.1179/0020296715Z.000000000256

there is a gap in knowledge in terms of functional performance (e.g. tribological performance) of the silver coating achieved through environmentally friendly silver electroplating processes.

\subsection{Metal Matrix Composite Coatings}

Metal matrix composite (MMC) coatings have had polymers added such as polytetrafluoroethylene (PTFE) particles, in order to produce a polymer composite surface coating with the advantage of being a metal coating with improved tribological properties due to the addition of the PTFE polymer. Polymers are attractive for being processed into thin films due to their low cost, versatility and ease of processing [11].

PTFE is a fluoropolymer which has a low coefficient of friction but which also resists oxidation whilst retaining high thermal and chemical stability [12]. However, PTFE degrades rapidly when subjected to ionising radiation in ambient temperatures [13]. The degradation occurs as the polymeric chains are rapidly broken when subjected to irradiation in the presence of air. In terms of tribological performance for PTFE, friction coefficients of around 0.05 have been obtained at high loads, low speeds and moderate temperatures $[14,15]$. In addition, the self-lubricating properties of PTFE has resulted in its common use as a solid lubricant [16].

The possibility of successfully co-depositing of metal and suspended particles through electroplating baths has been reported by Walsh and Leon; however, they have noted that electroplating factors such as geometry of the work-piece as well as bath agitation are important in this context [7]. At present, MMC coatings obtained through electroplating such as Nickel-PTFE (Ni-PTFE) are used commercially for both its decorative and functional advantages over the standard nickel coating [17], 
Accepted for publication in Transactions of Institute of Materials Finishing, doi: 10.1179/0020296715Z.000000000256

with improved wear properties such as non-galling, dry lubricity, lower friction as well as improved corrosion resistance [17-20]. On the other hand, previous research involving Ag-PTFE MMC coatings have been carried out for applications such as anti-microbial[21], conductivity [22] and improved corrosion resistance [23].

A potential application of Ag-PTFE MMC coatings is for threaded connections, where the surface coating on threaded connections used for connecting valves and pipes is crucial to the required sealability of the assembly as a whole. Key considerations for surface coatings on threaded connections include tribological factors, galling (wear as a result of the asperity ploughing between sliding surfaces), aesthetics and potentially even load bearing capabilities depending on its application. Functional aspects such as the tribological qualities of the coating will affect the integrity and sealability of the connection during its assembly. On the other hand, the variation in galling resistance and friction affects the make-up torque and interfacial contact pressure of the assembly. Silver is a conventional noble material used as a coating material when considering corrosion resistance with dry lubrication properties for non-cost prohibitive applications such as aerospace with improved benefits over Nickel [24]. It would be desirable for the Ag-PTFE MMC coating on stainless steel developed to exhibit improved dry lubrication properties and good adhesion. Any defects in silver electroplating on stainless steel are prone to corrosion which ultimately leads to the failure of the protective film in harsh environments. There is also the potential for improved corrosion resistance through the embedding of PTFE particles in defects on the surface through the electroplating process [21].

\subsection{Aims}


Accepted for publication in Transactions of Institute of Materials Finishing, doi: 10.1179/0020296715Z.000000000256

In this study, we report our attempts to develop and deposit a self-lubricating AgPTFE MMC coating which improves on the existing self-lubrication properties of silver coatings produced using environmentally friendly silver electroplating techniques. Friction, adhesion and galling of the Ag-PTFE MMC coating were investigated on 304 stainless steel plates as the first phase of the research with the ultimate goal of improving the tribological performance of threaded connections through the Ag-PTFE coating.

\subsection{Experimental Materials and Methods}

\subsection{Electroplating parameters}

During this investigation, the electroplating was carried out using a Rapid Electronics DC power supply model HY3003D. The current density throughout each experiment run and between runs was between $0.13 \mathrm{~A} / \mathrm{dm}^{2}$ and $0.15 \mathrm{~A} / \mathrm{dm}^{2}$. Elemental analysis through energy-dispersive X-ray spectroscopy (EDS) was carried out for all the samples to ensure that Ag-PTFE has been successfully deposited on the substrate. For the substrate material, ANSI 304 stainless steel plate sample dimensions of approximately $25 \mathrm{~mm} \times 12 \mathrm{~mm} \times 1 \mathrm{~mm}$ were used, with a $3 \mathrm{~mm}$ diameter hole near one end to hang the sample during electroplating. The electroplating parameters used are detailed in Table 1. In this instance, succinimide is added as the complexing agent to the electrolytic solution. The PTFE used was supplied by Sigma-Aldrich with particle sizes quoted by the manufacturer of between $0.15 \mu \mathrm{m}$ and $0.5 \mu \mathrm{m}$ (average particle sizes were $0.22 \mu \mathrm{m}), 60 w t . \%$ dispersion in $\mathrm{H}_{2} \mathrm{O}$. 
Accepted for publication in Transactions of Institute of Materials Finishing, doi: 10.1179/0020296715Z.000000000256

Table 1: Bath composition and operating conditions

\begin{tabular}{ll}
\hline Composition & Conditions \\
\hline Silver Nitrate $(\mathrm{g} / \mathrm{L})$ & $17-34$ \\
Succinimide $(\mathrm{g} / \mathrm{L})$ & $50-80$ \\
Potassium Hydroxide $(\mathrm{g} / \mathrm{L})$ & $12-14$ \\
Solution $\mathrm{pH}$ & $8.5-9.5$ \\
Temperature $\left({ }^{\circ} \mathrm{C}\right)$ & $28-32$ \\
Current Density $\left(\mathrm{A} / \mathrm{dm}^{2}\right)$ & $0.13-0.15$ \\
\hline
\end{tabular}

A trial and error analysis process was initially conducted to better understand the impacts of the various electroplating parameters on the quality of the PTFE surface coating produced and its tribological performance on ANSI 304 stainless steel. EDS analysis of the initial plated samples was carried out as part of the SEM analysis to determine the presence of PTFE $\left(\mathrm{C}_{2} \mathrm{~F}_{4}\right)_{\mathrm{n}}$ through carbon and fluorine elements on surface characteristics of the stainless steel substrate. The initial trial variables were then narrowed down to the five variables indicated in Table 2.

Table 2: The variables that were investigated for the Ag-PTFE surface coating

\begin{tabular}{|c|c|}
\hline Variable & Values \\
\hline PTFE Content (mL/L) & $50 / 100$ \\
\hline Electroplating time (seconds) & $300 / 600$ \\
\hline $\begin{array}{l}\text { Electroplating bath agitation speed } \\
\text { (RPM) }\end{array}$ & $100 / 200$ \\
\hline Voltage (V) & $0.5 / 0.8$ \\
\hline Presence of potassium nitrate $(\mathrm{g} / \mathrm{L})$ & 0/16.7 added \\
\hline
\end{tabular}


Accepted for publication in Transactions of Institute of Materials Finishing, doi: 10.1179/0020296715Z.000000000256

Surface preparation and a suitable clean sequence are an essential part of the electroplating process. This ensures that surfaces of the samples are consistently clean and free from contamination. The sample surfaces were cleaned using an alkaline cleaning solution and immersed in an ultrasonic cleaner for approximately 300 seconds. Following this, the samples were immersed in a Hydrochloric Acid (HCL) solution of $5 \% \mathrm{w} / \mathrm{v}$ for approximately 240 seconds. The full cleaning sequence is detailed in Table 3.

Table 3: The pre-treatment and coating procedures for Ag-PTFE

\begin{tabular}{ll}
\hline Procedures & Conditions \\
\hline Alkaline cleaning & $300 \mathrm{~s}$ at $\sim 20^{\circ} \mathrm{C}$ \\
Rinsing Temperature & $\sim 20^{\circ} \mathrm{C}$ \\
Acid etching, $5 \% \mathrm{w} / \mathrm{v} \mathrm{HCL}$ & $180-300 \mathrm{~s}$ at $\sim 20^{\circ} \mathrm{C}$ \\
Rinsing Temperature & $\sim 20^{\circ} \mathrm{C}$ \\
Ag-PTFE Electroplating & $28-32^{\circ} \mathrm{C}, 300 / 600 \mathrm{~s}$ \\
Rinsing & $\sim 20^{\circ} \mathrm{C}$ \\
Drying & $60^{\circ} \mathrm{C}$ \\
\hline
\end{tabular}

The coatings obtained under these conditions exhibit shiny silver finish which are free of blisters or holes. However, subsequent atmospheric exposure does cause a degree of tarnishing as illustrated in Figure 1. 


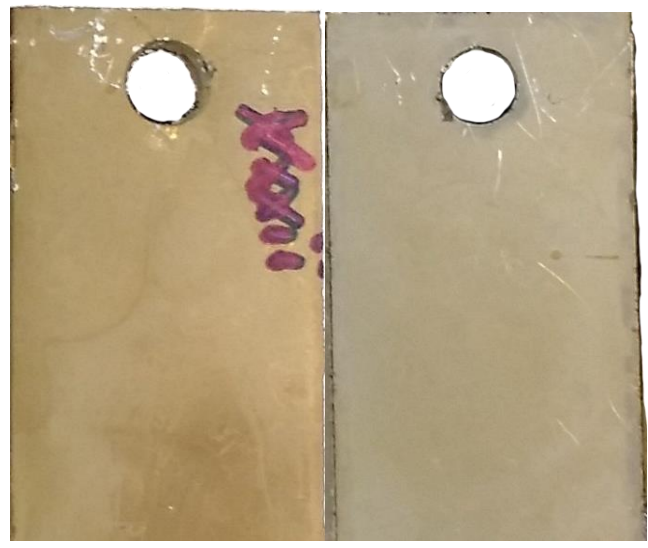

Figure 1: Tarnished sample (left) and bright sample (right). Parameters (left sample): PTFE 50ml/L, Plating time 600 s, Agitation speed 200 RPM, Voltage 0.8 $V$, Potassium nitrate $0 \mathrm{~g} / \mathrm{L}$. Parameters (right sample): PTFE 50ml/L, Plating time 600 s, Agitation speed 100 RPM, Voltage 0.8 V, Potassium nitrate $0 \mathrm{~g} / \mathrm{L}$.

\subsection{Microscopic characterisation}

Microscopy was used to examine the surface roughness prior to electroplating in order to determine silver and PTFE surface coating content after electroplating and to observe the extent of the wear on the sample after testing was carried out.

The SEM microscopy was conducted on the JEOL 6500 and 7100 instruments available at Plymouth Electron Microscope Centre. This included inspecting the surface morphology and determining the silver and PTFE surface coating content in wt\% using EDS analysis. The elements of interest were silver ( $\mathrm{Ag})$ as well as both fluorine $(\mathrm{F})$ and carbon $(\mathrm{C})$ from PTFE with chemical formula $\left(\mathrm{C}_{2} \mathrm{~F}_{4}\right)_{\mathrm{n}}$. Quantitative data from the EDS analysis were compiled and compared across all the DoE samples analysed with averages from three random sites on each sample at the same magnification levels.

In addition, XPS was carried out in order to better understand the surface chemistry of the Ag-PTFE electroplating. The XPS microscopy work was carried out by Newcastle University's NEXUS facility. Only a small number of samples could be 
Accepted for publication in Transactions of Institute of Materials Finishing, doi: 10.1179/0020296715Z.000000000256

tested at NEXUS due to the limited availability of the facility. Initial results from the SEM and EDS analysis was used to determine the selection of samples to be analysed; these included a control sample of pure electroplated silver fabricated using the non-cyanide electroplating process.

Finally, optical microscopy was used to examine and quantify the surface roughness of the samples prior to carrying out the electroplating. This was carried out on an Olympus LEXT OLS3000 Laser Confocal microscope. This was carried out to ensure a similar surface roughness on all pre-plated samples. Following testing, the inspection and analysis of the wear track was carried out using an Olympus BX-60M optical microscope.

\subsection{Tribological and mechanical testing}

Friction tests were carried out using a bespoke bi-directional tribometer as illustrated in Figure 2. The details of the design of the test rig have been reported by Le et al [25]. In this test, the sample is mounted at a set $5^{\circ}$ slope with the replaceable, $3 \mathrm{~mm}$ diameter, grade 10 AISI 52100 chrome steel spherical friction pin (Hardness: 60-67 $\mathrm{HRC}$ ) resting on the sample at the datum state. The spherical friction pin is held at a set distance from its mounting point on the tribometer's main shaft using a metal arm to which strain gauges are attached in a half-bridge configuration. As the friction pin is moved in a linear direction by the motor, the strain gauges measure the vertical displacement while the fibre optic sensor measures the horizontal displacement. These displacement values expressed in voltage are recorded every 10 milliseconds and are used to calculate the dynamic frictional coefficient. 


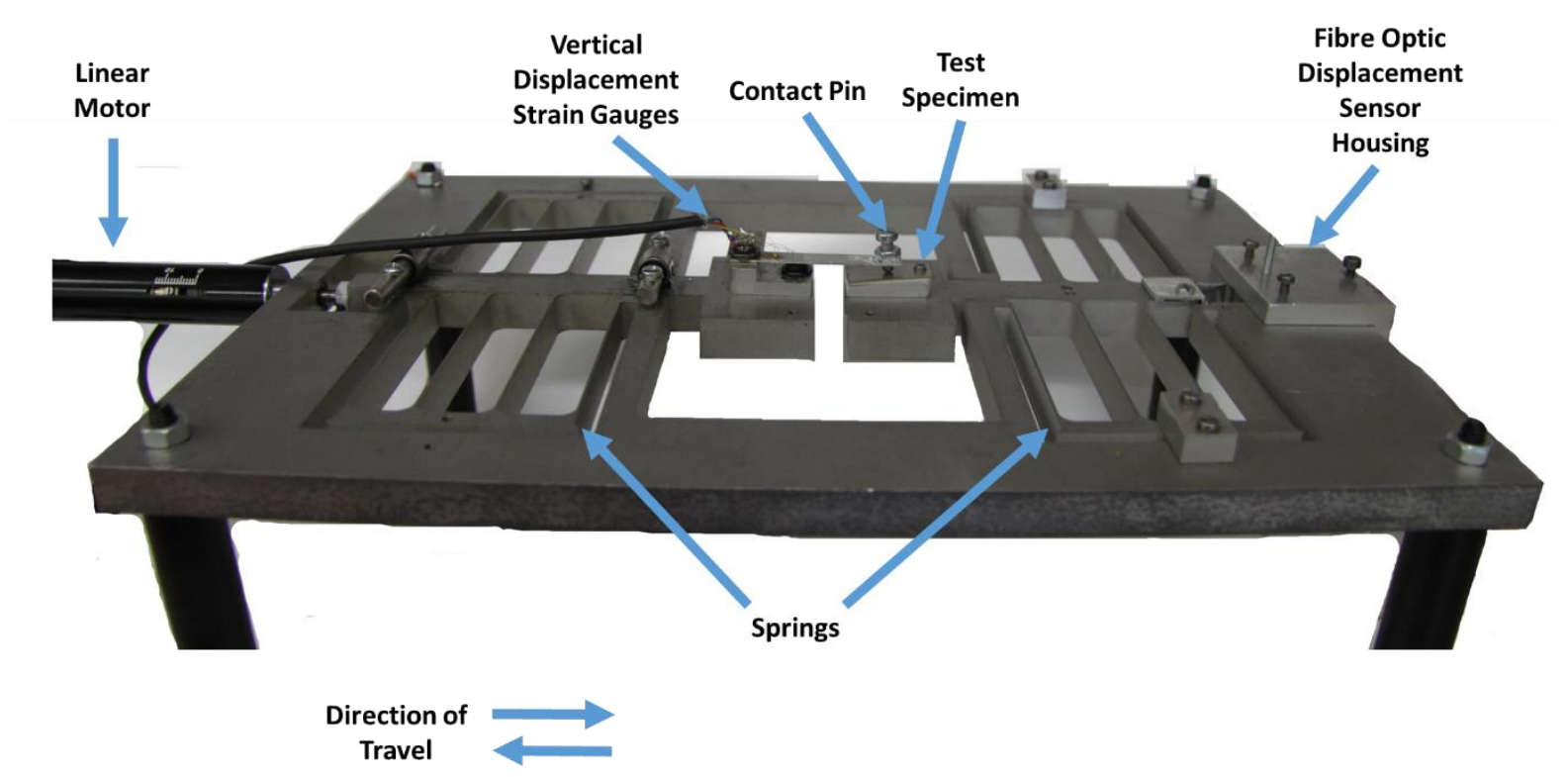

Figure 2: The bi-directional tribometer

A linear relationship of voltage to weight was observed from the calibration of both the strain gauges and fibre optic displacement sensor within required force range. In addition, a consistency of output results were obtained during multiple calibration runs for both the strain gauges and fibre optic displacement sensor. The calibration of the system suggests that the tribometer is capable of producing reliable and repeatable output results. The friction coefficient was calculated based on the forces acting on the sample surface with friction pin resting on top. The acquisition of voltage output data from both the strain gauges and fibre optic sensor were through Labview 2012 version 12 which was linked to a National Instruments NI USB-6210 data acquisition module.

Adhesion tests were conducted using an Instron tensile testing machine as illustrated in Figure 3 with a maximum force transducer capacity of $5 \mathrm{kN}$. ANSI 304 stainless steel rods of $6 \mathrm{~mm}$ diameter were fabricated with a hole in one end to allow a metal wire to be attached to the machine. The other end of the stainless steel was polished 
Accepted for publication in Transactions of Institute of Materials Finishing, doi: 10.1179/0020296715Z.000000000256

to a mirror finish and cleaned using alkaline solution prior to being attached to the sample using a Vishay general purpose adhesive. Care was taken to ensure that the correct amount of adhesive was used during the mounting of the sample. After curing of adhesive between the test rod and the sample, the Instron machine test profile was set to carry out the tensile test at a speed of $2 \mathrm{~mm} / \mathrm{min}$.

Wear inspection was carried out on all the friction test samples to compare coating performance in relation to the electroplating conditions. This was carried out with the aid of optical microscopy.

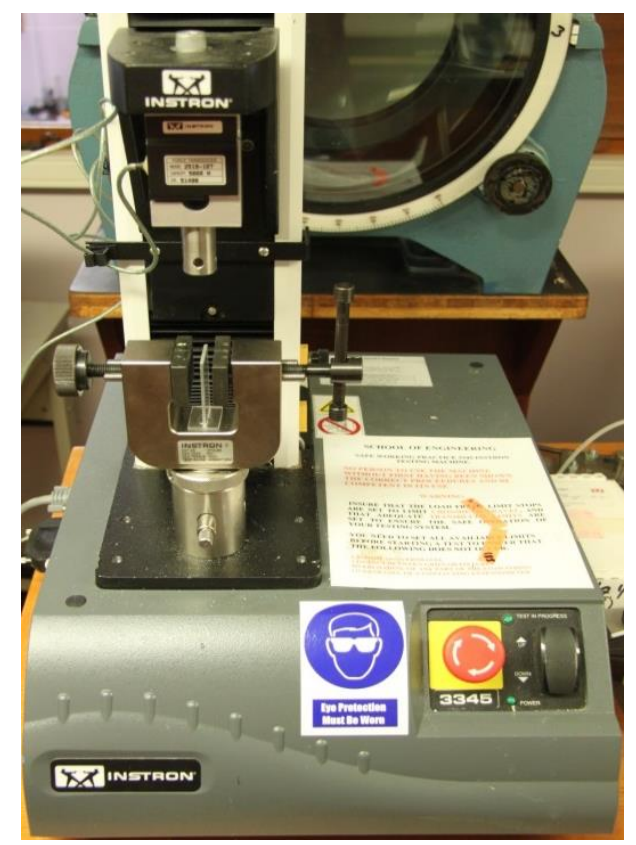

Figure 3: The Instron tensile testing machine

\subsection{Results and Discussions}

\subsection{PTFE content in the coating}

An initial inspection of the surface morphology is illustrated in Figure 4 for the control sample of pure silver electroplating. This was conducted to establish the effectiveness of the succinimide electroplating bath. At 40,000x magnification, the 
Accepted for publication in Transactions of Institute of Materials Finishing, doi: 10.1179/0020296715Z.000000000256

surface morphology is comprised of nugget like silver particles. These silver particles demonstrate good adherence to the substrate by covering all of the substrate surface area, suggesting that succinimide is a suitable cyanide alternative to silver electroplating.

The typical surface morphology for the Ag-PTFE MMC coating (obtained at 5000x magnification) is illustrated in Figure 5. At this level of magnification, the grain boundaries of the substrate are clearly visible and the plated thin film layer was able to cover minor pits and imperfections on the substrate. The failure of the plated layer to cover larger pits and imperfections suggest that the coating is in the form of a thin film of nano-metre to micro-meter thickness. Larger silver particles are visible as being spherical in shape, bright and light coloured. In general the plated coatings were observed to have full coverage of silver particles in varying sizes.

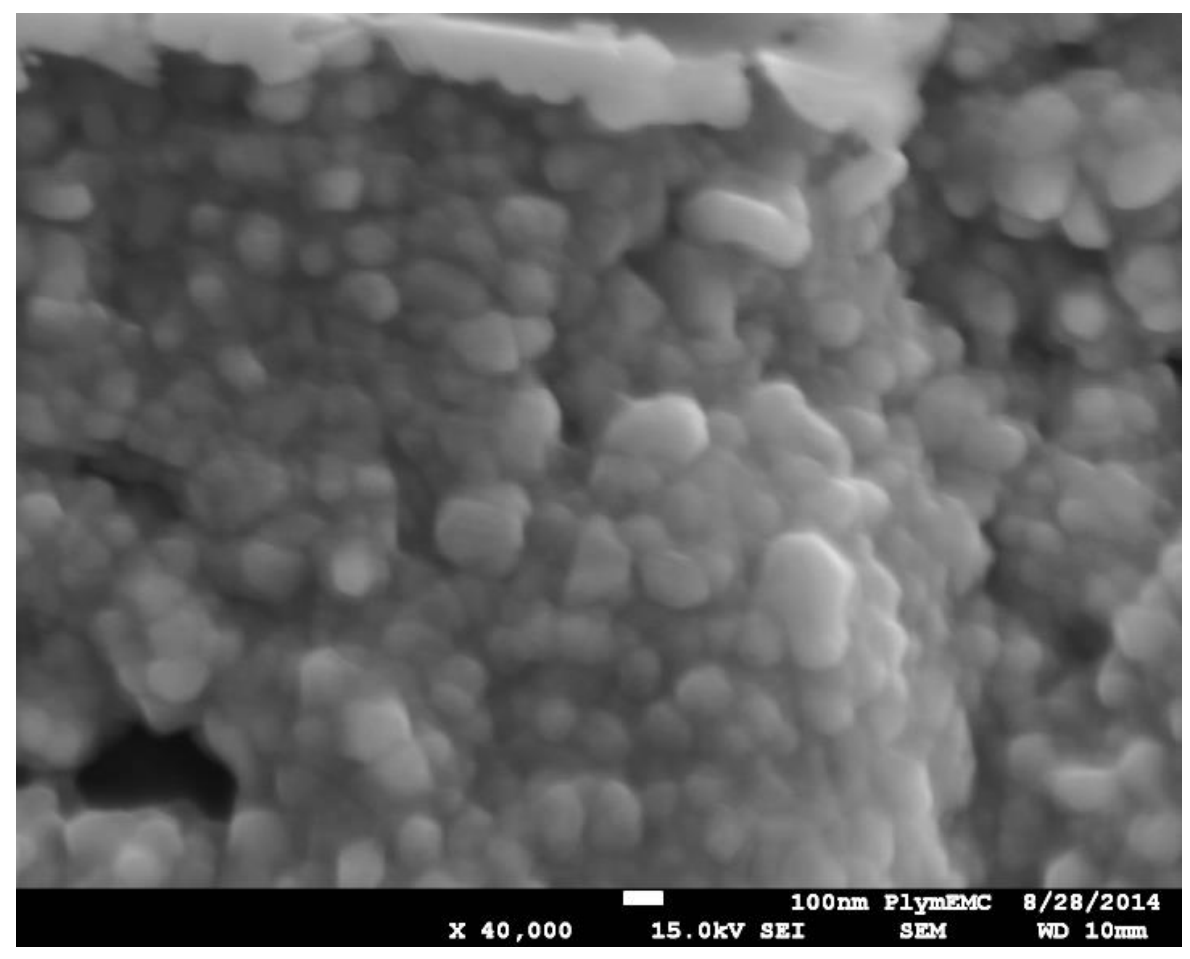

Figure 4: SEM image at 40000x magnification showing uniform distribution of silver on the sample surface using the non-cyanide silver electroplating process. Parameters: Plating time 600 s, Agitation speed 200 RPM, Voltage $0.5 \mathrm{~V}$. 


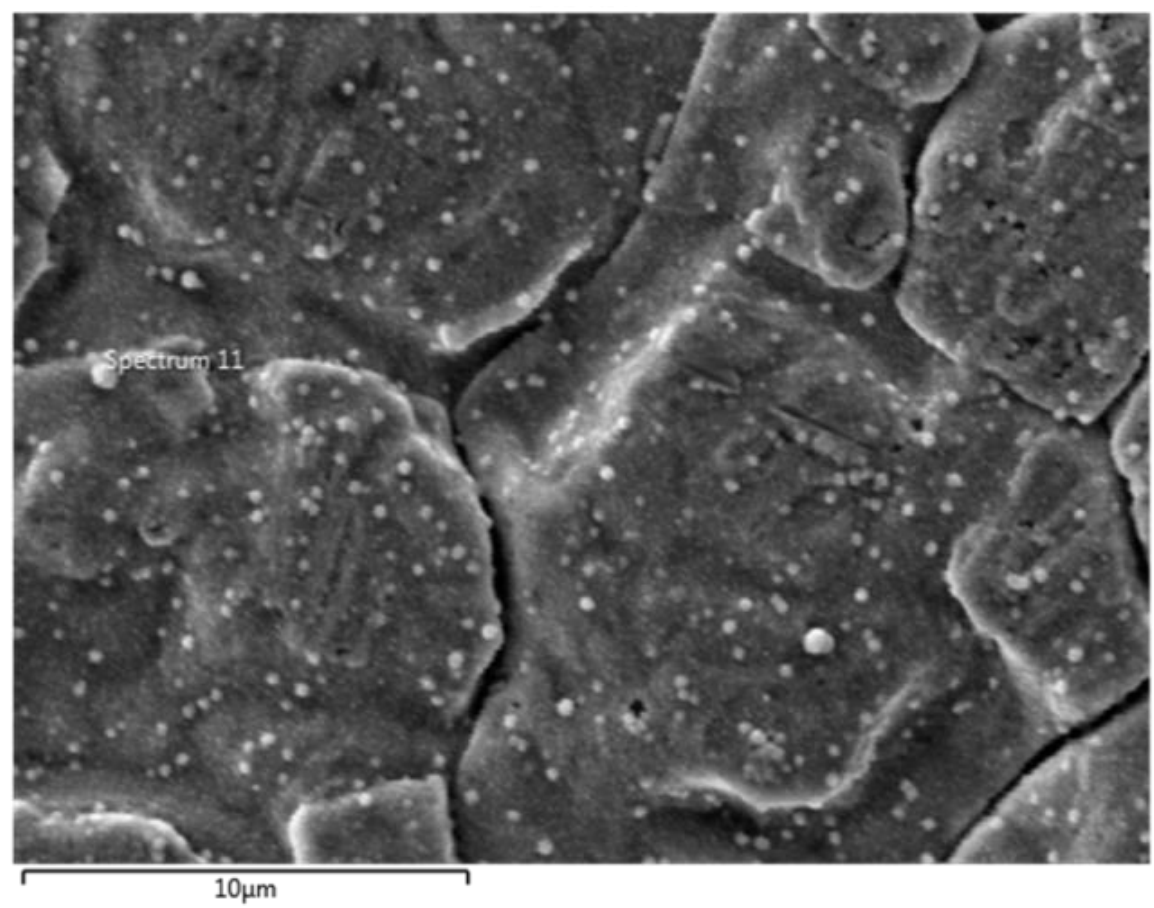

Figure 5: SEM image at 5,000x magnification showing grain boundaries of the substrate layer and evenly distributed silver particles as being spherical in shape, with larger silver particles being bright and light coloured. Parameters: PTFE $100 \mathrm{ml} / \mathrm{L}$, Plating time $300 \mathrm{~s}$, Agitation speed 200 RPM, Voltage $0.5 \mathrm{~V}$, Potassium nitrate $0 \mathrm{~g} / \mathrm{L}$.

The different bath conditions yielded varying results for Ag-PTFE coverage of the substrate. Typical poor distribution of plated particles on the substrate surface is illustrated in Figure 6a. The poor distribution has resulted in clusters of randomly dispersed silver particles on the substrate being visible at 30,000x magnification. This can be attributed to less than optimal bath variable conditions for electroplating, low surface tension for PTFE and less effective surfactant in the bath. On the other hand, typical good distribution of plated particles on the substrate surface is illustrated in Figure $6 \mathrm{~b}$ indicating optimal bath variable conditions for electroplating, and Ag-PTFE particles of varying sizes adhere fully to the substrate surface. By controlling the bath variables during electroplating, the quality and thickness of the coating can be finetuned. The quality of particle distribution on the substrate surface based on varying bath conditions has been quantified using adhesion tests reported in Section 3.2. 


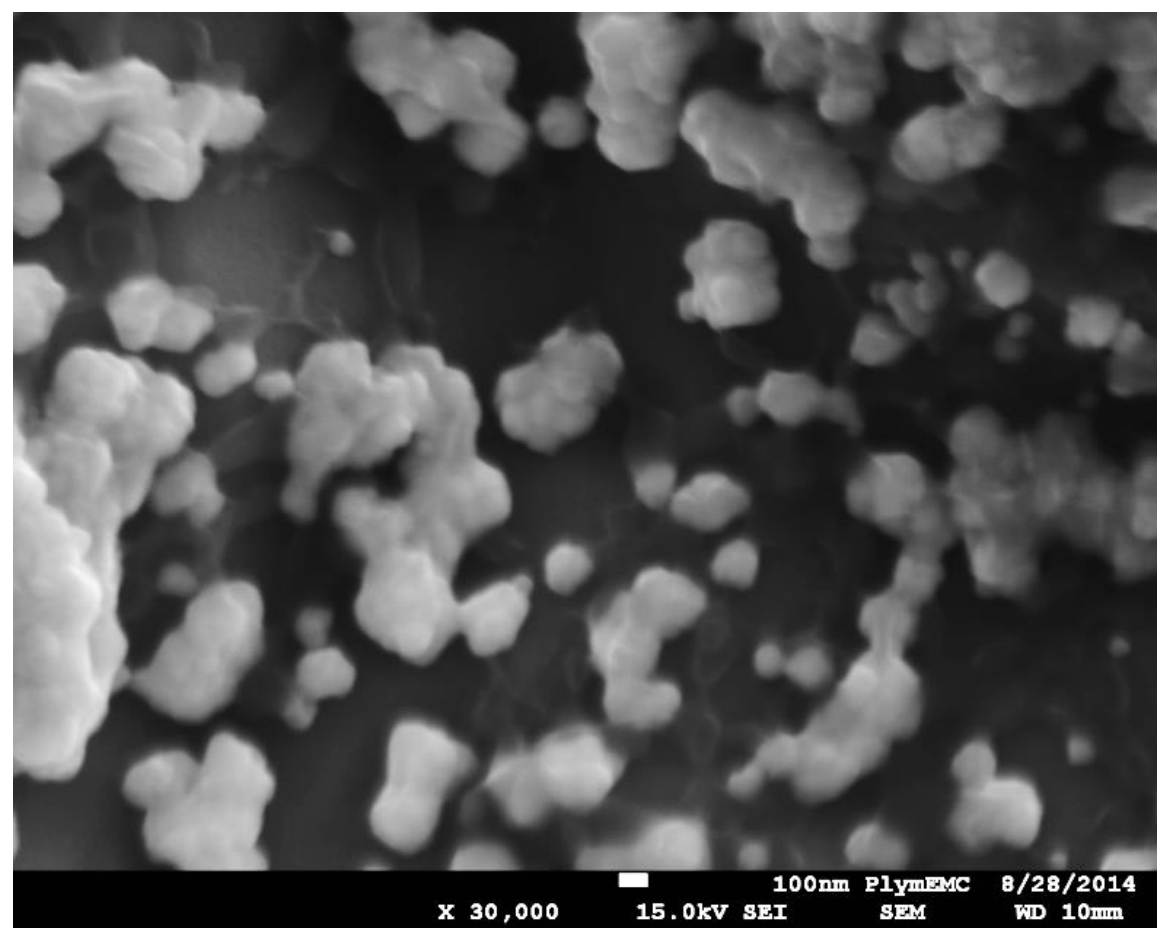

Figure 6a: SEM image at 30000x magnification showing random clusters of dispersed silver on the substrate in a poor quality Ag-PTFE coating. Parameters: PTFE 100ml/L, Plating time 300 s, Agitation speed 100 RPM, Voltage $0.5 \mathrm{~V}$, Potassium nitrate $16.7 \mathrm{~g} / \mathrm{L}$.

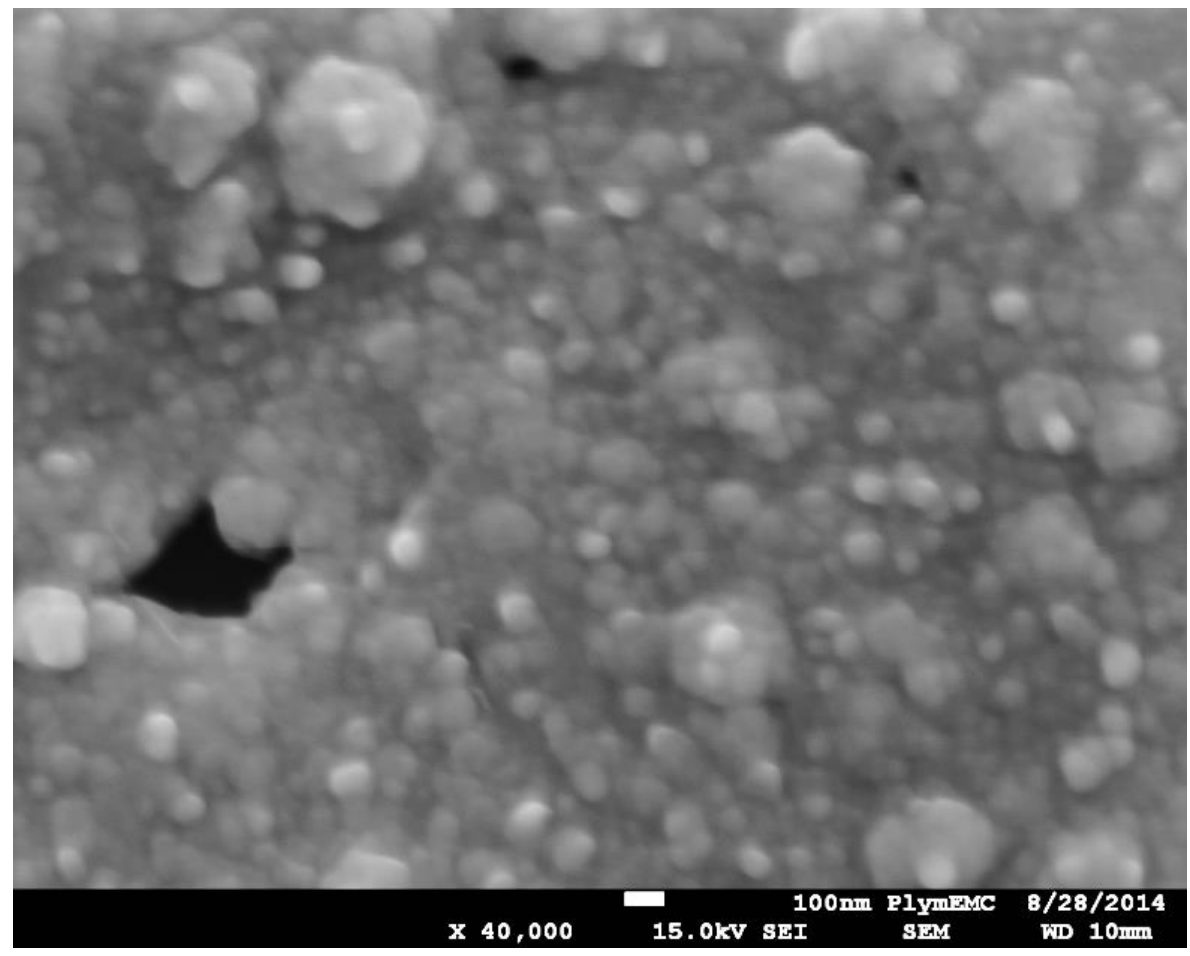

Figure 6b: SEM image at 40000x magnification showing uniform Ag-PTFE coating of varied particle size in a high quality Ag-PTFE coating. Parameters: PTFE 50mI/L, Plating time $300 \mathrm{~s}$, Agitation speed 100 RPM, Voltage $0.8 \mathrm{~V}$, Potassium nitrate $0 \mathrm{~g} / \mathrm{L}$. 
Accepted for publication in Transactions of Institute of Materials Finishing, doi: 10.1179/0020296715Z.000000000256

EDS results carried out as part of the SEM analysis identified elements as weight percentage which included that of silver $(\mathrm{Ag})$, fluorine $(\mathrm{F})$, Oxygen $(\mathrm{O})$ and carbon $(\mathrm{C})$ from the electroplated layer as well as elements of iron (Fe), chromium (Cr), nickel (Ni), manganese $(\mathrm{Mn})$, and Silicon (Si) from the substrate. This provides evidence that the electroplating is in the form of a thin film which can be penetrated by the EDS electrons. The carbon element identified from the substrate layer used in the manufacture of ANSI 304 stainless steel would be in minimal amounts. This suggests that the majority of the element would be from the electroplated layer. However, to avoid potential errors, fluorine was used as the basis of determining the presence of PTFE. Based on the EDS wt.\% analysis, silver and fluorine content on the surface of the samples were between 87.99 wt.\% -99.82 wt.\% and 0.18 wt.\% -12.01 wt.\% as illustrated in Figures 7a and 7b respectively. This confirms that Ag-PTFE layer has been successfully plated through the non-cyanide electroplating process.

Based on further analysis of the EDS data, it can be concluded that there is no correlation between the amounts of PTFE added into the electroplating bath to the amount of PTFE detected through EDS analysis. The data obtained from this research support findings from other authors that bath electroplating parameters are critical in electroplating without the use of suitable surfactants. It is likely that without the presence of a suitable surfactant during the Ag-PTFE electroplating process, the PTFE particles struggled to gain the surface tension required for good adhesion and subsequently good electroplating quality.

The quantitative comparison of element data obtained from the research with the electroplating bath variables initially suggest that the samples with the highest amounts of $\mathrm{Ag}$ (and inversely lowest amounts of PTFE) occur when no potassium 
Accepted for publication in Transactions of Institute of Materials Finishing, doi: 10.1179/0020296715Z.000000000256

nitrate is added into the bath (i.e. bath 7,29 ). However, bath 13 with no potassium nitrate has also contributed to the opposite extreme in the results for having the highest amount of PTFE on the plated surface. It can therefore be concluded that potassium nitrate addition into the electroplating bath has no correlation with the content of the electroplated Ag-PTFE composite coating.

XPS results confirmed the presence of a plated Ag-PTFE layer through the detection of silver, carbon and fluorine elements on the surfaces of the samples. However, the carbon and fluorine signals were only detected briefly. This occurred as the analysis process exposed ionising radiation onto the sample which degraded the thin layer of PTFE, as documented in previously published literature [13]. As a result, this has limited the scope for the XPS analysis.

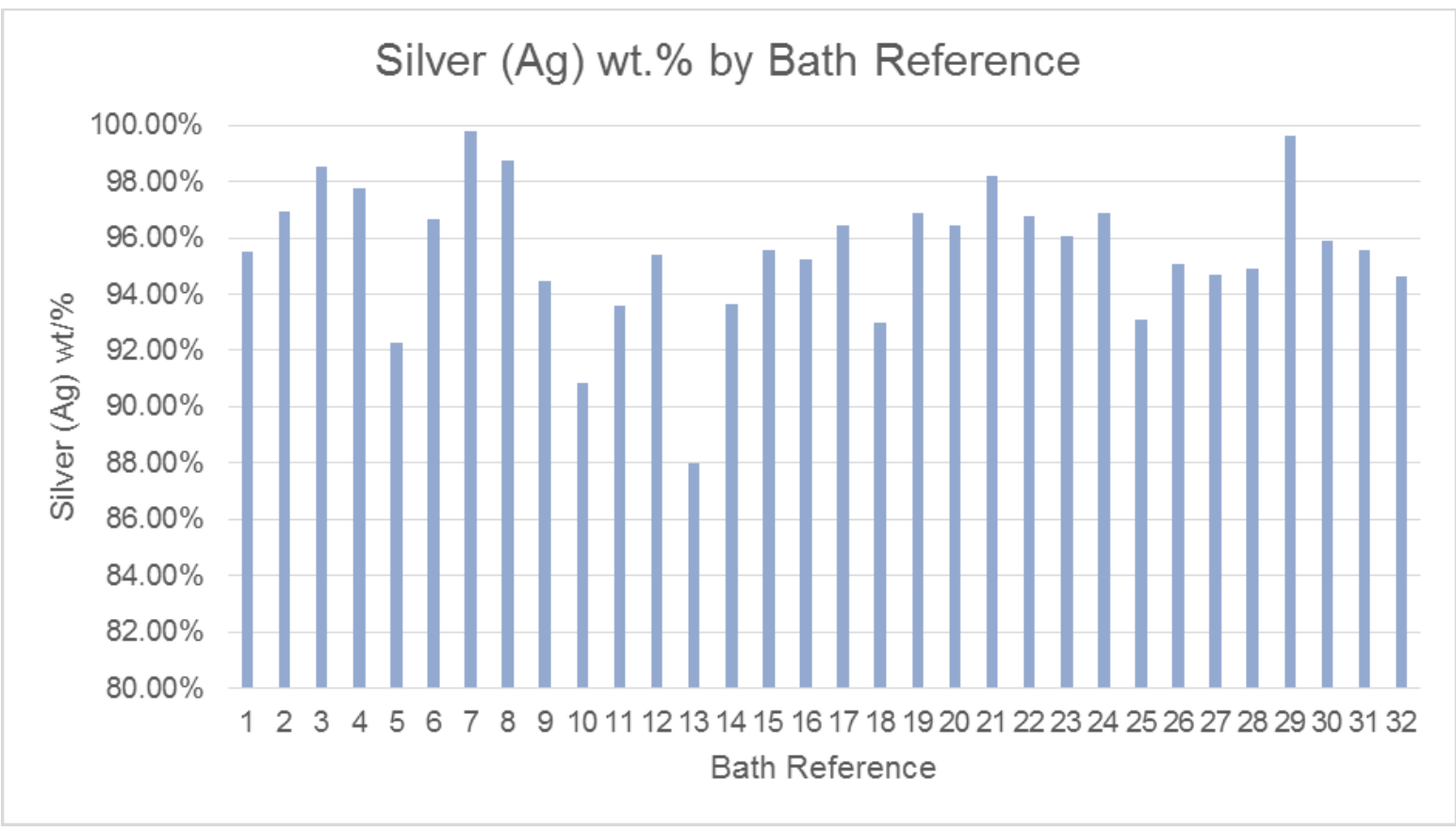

Figure $7 a$ : Silver (Ag) wt.\% by bath reference suggesting success in the noncyanide alternative bath for silver electroplating 


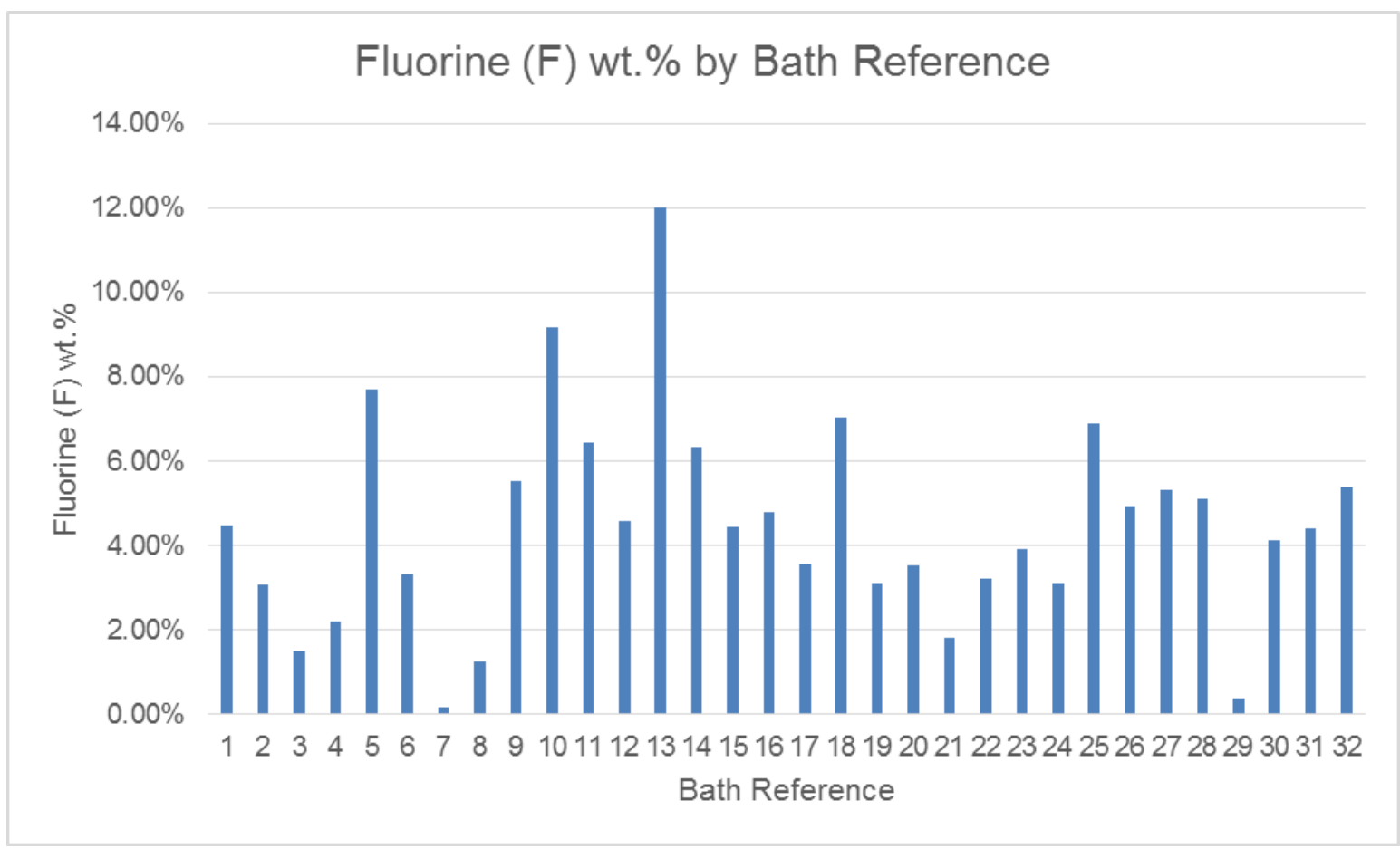

Figure $7 \mathrm{~b}$ : Fluorine $(F)$ wt.\% by bath reference indicating the success of AgPTFE synthesis through a non-cyanide electroplating bath

\subsection{Effect of PTFE content on tribology}

Friction coefficients were higher at the start of the tribometer run as well as during changes in direction. This was to be expected as the friction pin would have to overcome static friction prior to moving. Runs carried out on the tribometer to establish friction coefficients showed dynamic friction coefficients of between 0.23 and 0.51 was achievable between samples tested, with an average of 0.34 . These results have been summarised in Figure 8 . The best friction coefficient was obtained from bath reference 30 , under plating parameters of PTFE $100 \mathrm{ml} / \mathrm{L}$, Plating time 300 s, Agitation speed 200 RPM, Voltage $0.8 \mathrm{~V}$ with no potassium nitrate added.

The friction data for pure silver electroplating on the other hand resulted in friction coefficients of 0.6 . The results indicate that the Ag-PTFE MMC coating offers improved overall tribological performance over a pure silver electroplating. The friction coefficients obtained from different electroplating baths indicate the potential 
Accepted for publication in Transactions of Institute of Materials Finishing, doi: 10.1179/0020296715Z.000000000256

of reducing the friction coefficient by up to $62 \%$ by varying different bath parameters. It also suggests that optimisation of bath parameters might be able to further improve the coating quality and tribological performance.

Further analysis of the data obtained shows no correlation between amounts of PTFE on the surface with the friction performance of the coating. All of the samples tested on the tribometer were not subjected to additional surface finishing prior to testing. Therefore, one possible cause of this might be varying surface roughness obtained after electroplating, which is a potential area for future research.

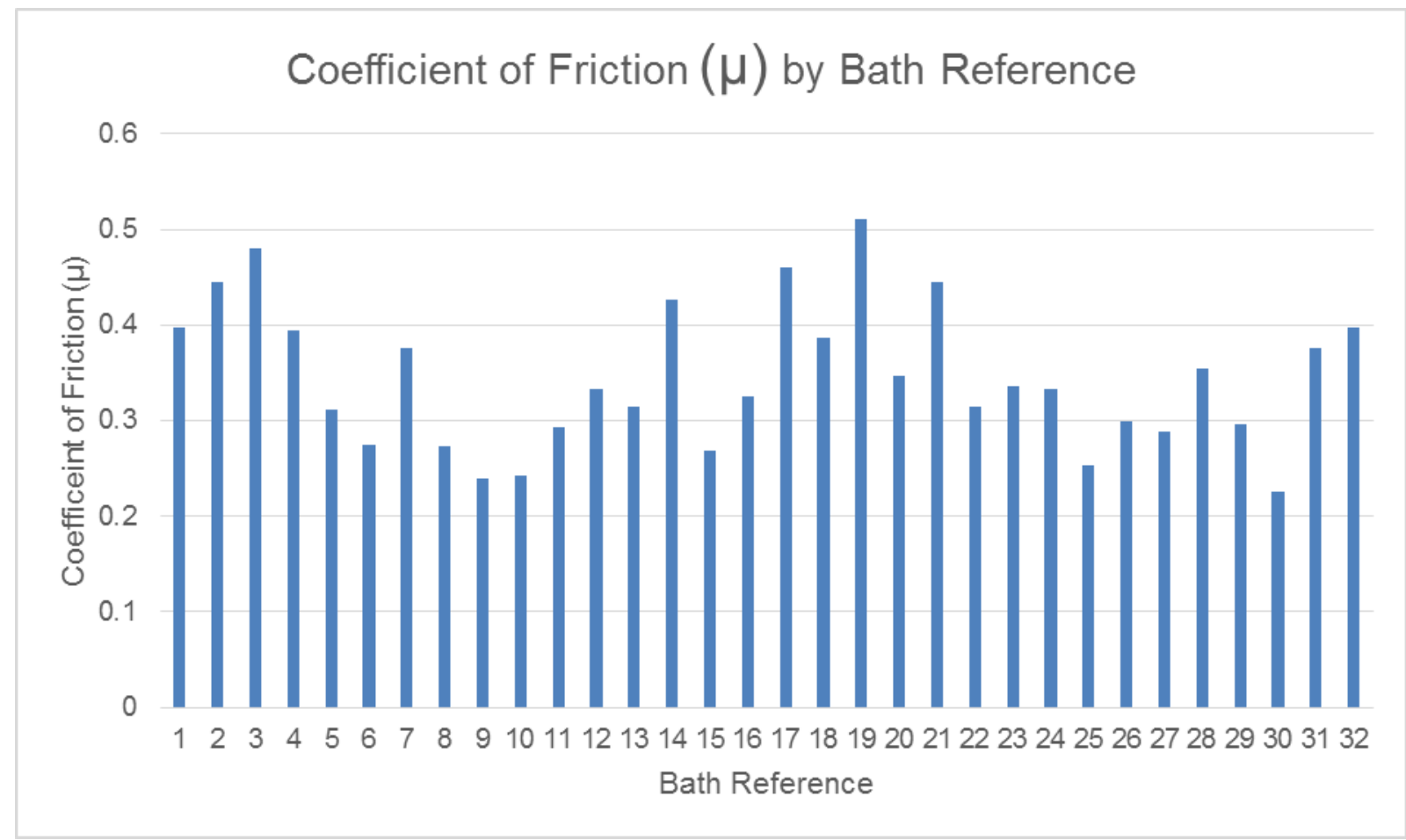

Figure 8: Coefficient of friction by electroplating bath reference for Ag-PTFE with an average of 0.34 and range of between 0.23 and 0.51

\subsection{Effects of PTFE content on adhesion}

Adhesion tests carried out showed maximum adhesion strength of $2.5 \mathrm{MPa}$ was achievable between the Ag-PTFE sample runs illustrated in Figure 9. On the other 
Accepted for publication in Transactions of Institute of Materials Finishing, doi: 10.1179/0020296715Z.000000000256

hand, the maximum adhesion strength for pure silver electroplating of $4.5 \mathrm{MPa}$ was achieved. The comparison of data suggests that a reduction of approximately $44 \%$ in maximum adhesion strength is a result of PTFE addition into the electroplating process. The review of electroplating bath parameters with electroplating adhesion performance has concluded that there is an inverse relation between the PTFE content in the electroplating bath with the electroplating adhesion performance. The higher amounts of PTFE in the electroplating bath which resulted in lower adhesion performance might be due to the lack of a suitable surfactant to ensure adhesion of PTFE particles during the electroplating process.

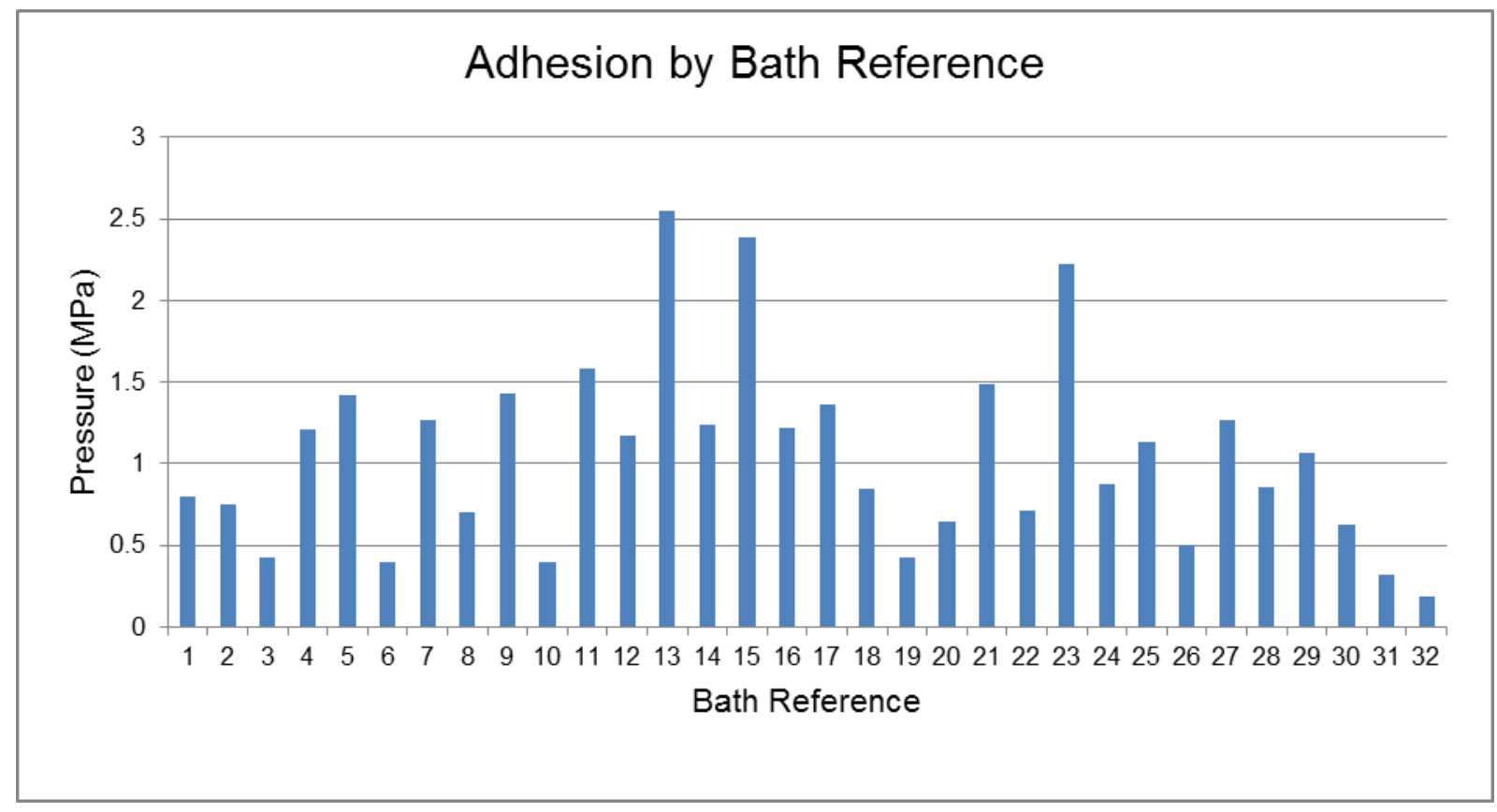

Figure 9: Adhesion performance by electroplating bath reference with a range of between 2.5MPa and 0.2MPa

Furthermore, the adhesion data suggests that there is no direct correlation between adhesion and friction coefficients in this instance. Based on the data obtained, it can be concluded that high adhesion strength between the surface coating and the substrate will not result in low frictional coefficients due to increased wear resistance. The wear tracks inspected using the optical microscope after the sample was tested 
Accepted for publication in Transactions of Institute of Materials Finishing, doi: 10.1179/0020296715Z.000000000256

using the tribometer exhibited typical wear patterns of the plated surface material being eroded as shown in Figure 10. Most of the coating is removed on the wear track by the friction pin showing the shiny substrate below.

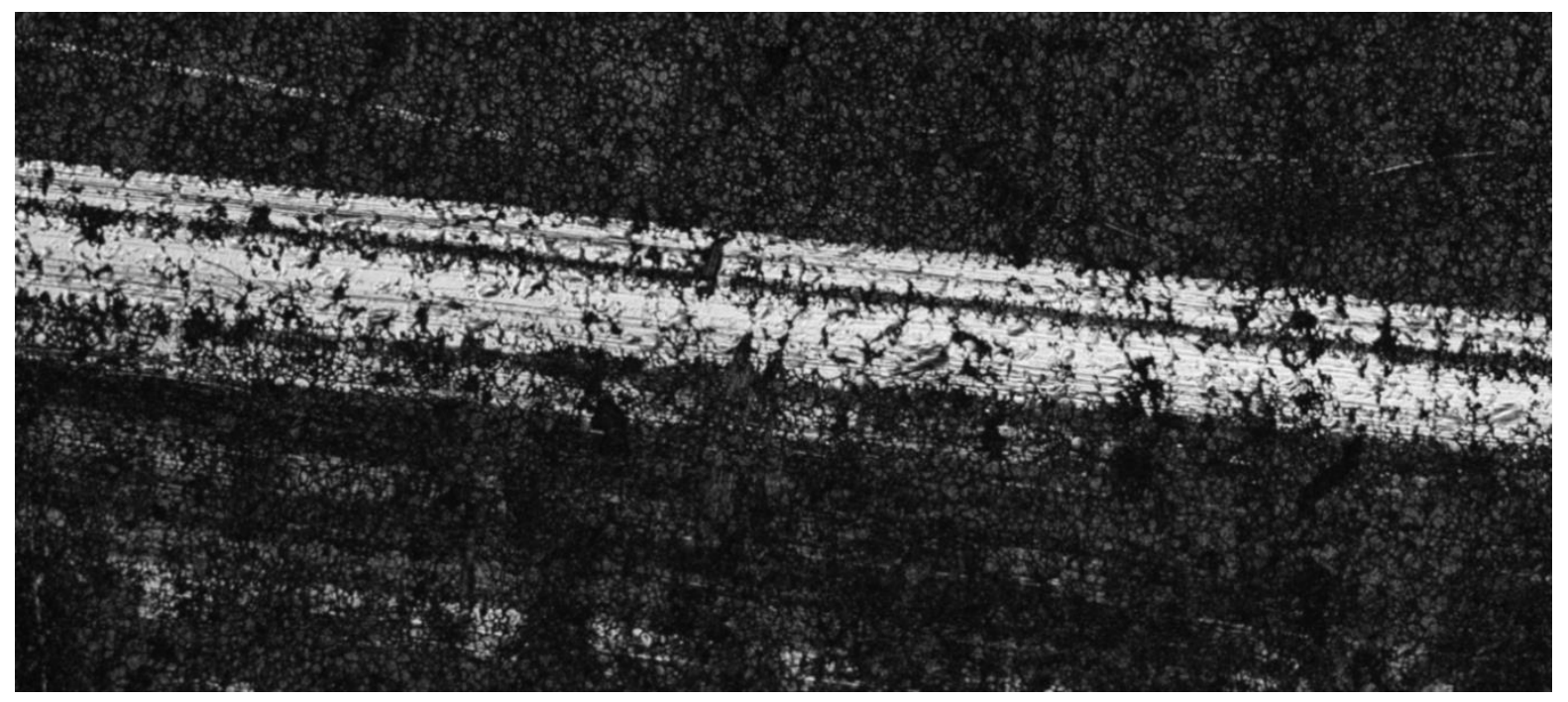

Figure 10: Typical wear pattern exhibited by samples. Parameters: PTFE 100ml/L, Plating time 300 s, Agitation speed 200 RPM, Voltage 0.5 V, Potassium nitrate $16.7 \mathrm{~g} / \mathrm{L}$.

\subsection{Conclusions}

This research investigated the effects of plating time, voltage, agitation speed, PTFE content and potassium nitrate content on the tribological and adhesion properties of electroplated Ag-PTFE using a non-cyanide electroplating bath. A self-lubricating AgPTFE MMC coating was successfully synthesized on the surface of ANSI 304 stainless steel without the use of a strike or addition of surfactant into a non-cyanide electroplating bath. The process is one that is scalable and integrates the corrosion performance of silver coating with the low frictional coefficient polymer PTFE. The resulting Ag-PTFE coating possesses superior tribological properties over the pure silver coating with friction coefficient of 0.23 achieved. This represents a $62 \%$ 
Accepted for publication in Transactions of Institute of Materials Finishing, doi: 10.1179/0020296715Z.000000000256

improvement over pure silver coating achieved from bath reference 30 , under plating parameters of PTFE $100 \mathrm{ml} / \mathrm{L}$, plating time 300 s, agitation speed 200 RPM, voltage $0.8 \mathrm{~V}$ with no potassium nitrate added. However, the Ag-PTFE electroplating process as a whole, sacrifices the maximum achievable coating adhesion strength by approximately $44 \%$ when compared to pure electroplated silver using the same process. For solid lubrication applications where higher adhesion strength is required, the optimum bath reference 13 may be used, with plating parameters of PTFE $100 \mathrm{~mL} / \mathrm{L}$, plating time $300 \mathrm{~s}$, agitation speed $100 \mathrm{RPM}$, voltage $0.5 \mathrm{~V}$ with no potassium nitrate added. This bath possesses the best adhesion strength while possessing improved tribological properties over standard pure silver coating, with a friction coefficient of 0.32 achieved, an improvement by $47 \%$. The adhesion strength of the Ag-PTFE MMC coating can potentially be further improved through the use of a suitable surfactant or a strike prior to electroplating for applications requiring strong coating adhesion. This non-cyanide MMC electroplating process is promising and can be scaled to an industrial level for high quality, self-lubricating applications where cost is not prohibitive.

\section{Acknowledgements}

The authors wish to acknowledge the support of the technicians at the engineering and chemistry department at Plymouth University for their assistance in this research. Special acknowledgements to the EPSRC scheme and Newcastle XPS team for supplying XPS facilities.

\section{References}

1. Knoll, W. and R.C. Advincula, Functional Polymer Films. 2013: Wiley.

2. Seshan, K., Handbook of Thin Film Deposition. 2012: Elsevier Science. 
Accepted for publication in Transactions of Institute of Materials Finishing, doi: 10.1179/0020296715Z.000000000256

3. Smith, D., Thin-Film Deposition: Principles and Practice. 1995: McGraw-Hill Education.

4. Alexi Antipov, Tribology Investigation of Silver and Gold Electroplated in Presence of Nano-diamonds and Nano-Alumina. 2009.

5. Blair, A., Silver plating. Metal Finishing, 2002. 100, Supplement 1(0): p. 284-290.

6. Boden, P.J., Disposal of toxic wastes-1. Electroplating and electrochemical machining wastes. Conservation \& Recycling, 1976. 1(1): p. 111-118.

7. Walsh, F.C. and C. Ponce de Leon, A review of the electrodeposition of metal matrix composite coatings by inclusion of particles in a metal layer: an established and diversifying technology. Transactions of the IMF, 2014. 92(2): p. 83-98.

8. Powers, J.V. and K.R. Grebe, Non-Cyanide Silver Plating Bath. 1968: United States.

9. Morrissey, R. Gold and Silver Plating Basics. 2011 22/02/2011 [cited 2014 13/08/2014]; Available from: http://www.pfonline.com/articles/gold-and-silver-platingbasics.

10. Morrissey, R. Noncyanide Silver Plating. s.a. [cited 2014 15/08/2014]; Available from: http://www.technic.com/apac/sites/default/files/assets/pdfs/literature/Noncyanide\%20

\section{Silver\%20Plating.pdf.}

11. Takele, H., et al., Plasmonic properties of Ag nanoclusters in various polymer matrices. Nanotechnology, 2006. 17(14): p. 3499.

12. Holmberg, K. and A. Matthews, Coatings Tribology: Properties, Mechanisms, Techniques and Applications in Surface Engineering. 2009: Elsevier Science.

13. Drobny, J., Fluoroplastics. 2006: iSmithers Rapra Publishing.

14. Lancaster, J.K., Accelerated wear testing of PTFE composite bearing materials. Tribology International, 1979. 12(2): p. 65-75.

15. Lu, X., et al., Surface characterization of polytetrafluoroethylene (PTFE) transfer films during rolling-sliding tribology tests using $X$-ray photoelectron spectroscopy. Wear, 2006. 261(10): p. 1155-1162.

16. Beckford, S., Y.A. Wang, and M. Zou, Wear-Resistant PTFE/SiO2 Nanoparticle Composite Films. Tribology Transactions, 2011. 54: p. 849-858.

17. Karl-Heinz, P., Dispersion Coatings with PTFE. Products Finishing, 1999. 63(2): p. 34-39.

18. Hadley, J.S. and L.E. Harland, ELECTROLESS NICKEL/PTFE COMPOSITE COATINGS. Metal Finishing, 1987. 85(12): p. 51-53.

19. Tulsi, S.S., Composite PTFE-Nickel coatings for low friction applications. Materials \& Design, 1983. 4(6): p. 919-923.

20. Kumar Dubey, M., J. Bijwe, and S.S.V. Ramakumar, PTFE based nano-lubricants. Wear, 2013. 306(1-2): p. 80-88.

21. Zhao, Q., Y. Liu, and C. Wang, Development and evaluation of electroless Ag-PTFE composite coatings with anti-microbial and anti-corrosion properties. Applied Surface Science, 2005. 252(5): p. 1620-1627.

22. Wei, $\mathrm{H}$. and $\mathrm{H}$. Eilers, Electrical conductivity of thin-film composites containing silver nanoparticles embedded in a dielectric fluoropolymer matrix. Thin Solid Films, 2008. 517(2): p. 575-581.

23. Fu, Y., et al., Ag-polytetrafluoroethylene composite coating on stainless steel as bipolar plate of proton exchange membrane fuel cell. Journal of Power Sources, 2008. 182(2): p. 580-584.

24. Richard T. Barrett, Nasa Reference Publication 1228: Fastener Design Material. 1990.

25. Le, H.R., et al., Tribological Characterisation of Air-Sprayed Epoxy-CNT Nanocomposite Coatings. Tribology Letters, 2012. 45(2): p. 301-308. 
Accepted for publication in Transactions of Institute of Materials Finishing, doi: 10.1179/0020296715Z.000000000256

\section{Appendix}

Appendix 1: Bath plating parameters

\begin{tabular}{|c|c|c|c|c|c|}
\hline Bath Ref & Time (s) & Voltage (V) & $\begin{array}{l}\text { Speed } \\
\text { (RPM) }\end{array}$ & $\begin{array}{l}\text { PTFE } \\
\text { Content } \\
\text { (mL/L) }\end{array}$ & $\begin{array}{c}\text { Potassium } \\
\text { Nitrate } \\
\text { Content } \\
(\mathrm{g} / \mathrm{L})\end{array}$ \\
\hline 1 & 300 & 0.5 & 100 & 50 & 16.7 \\
\hline 2 & 300 & 0.5 & 200 & 50 & 16.7 \\
\hline 3 & 600 & 0.5 & 100 & 50 & 16.7 \\
\hline 4 & 600 & 0.5 & 200 & 50 & 16.7 \\
\hline 5 & 300 & 0.5 & 100 & 50 & 0 \\
\hline 6 & 300 & 0.5 & 200 & 50 & 0 \\
\hline 7 & 600 & 0.5 & 100 & 50 & 0 \\
\hline 8 & 600 & 0.5 & 200 & 50 & 0 \\
\hline 9 & 300 & 0.5 & 100 & 100 & 16.7 \\
\hline 10 & 300 & 0.5 & 200 & 100 & 16.7 \\
\hline 11 & 600 & 0.5 & 100 & 100 & 16.7 \\
\hline 12 & 600 & 0.5 & 200 & 100 & 16.7 \\
\hline 13 & 300 & 0.5 & 100 & 100 & 0 \\
\hline 14 & 300 & 0.5 & 200 & 100 & 0 \\
\hline 15 & 600 & 0.5 & 100 & 100 & 0 \\
\hline 16 & 600 & 0.5 & 200 & 100 & 0 \\
\hline 17 & 300 & 0.8 & 100 & 50 & 16.7 \\
\hline 18 & 300 & 0.8 & 200 & 50 & 16.7 \\
\hline 19 & 600 & 0.8 & 100 & 50 & 16.7 \\
\hline 20 & 600 & 0.8 & 200 & 50 & 16.7 \\
\hline 21 & 300 & 0.8 & 100 & 50 & 0 \\
\hline 22 & 300 & 0.8 & 200 & 50 & 0 \\
\hline 23 & 600 & 0.8 & 100 & 50 & 0 \\
\hline 24 & 600 & 0.8 & 200 & 50 & 0 \\
\hline 25 & 300 & 0.8 & 100 & 100 & 16.7 \\
\hline 26 & 300 & 0.8 & 200 & 100 & 16.7 \\
\hline 27 & 600 & 0.8 & 100 & 100 & 16.7 \\
\hline 28 & 600 & 0.8 & 200 & 100 & 16.7 \\
\hline 29 & 300 & 0.8 & 100 & 100 & 0 \\
\hline 30 & 300 & 0.8 & 200 & 100 & 0 \\
\hline 31 & 600 & 0.8 & 100 & 100 & 0 \\
\hline 32 & 600 & 0.8 & 200 & 100 & 0 \\
\hline
\end{tabular}

